\title{
Correlation of Autophagosome Formation with Degradation and Endocytosis Arabidopsis Regulator of G-Protein Signaling (RGS1) through ATG8a
}

\author{
Yue Jiao ${ }^{1,2}$, Miroslav Srba ${ }^{3}$, Jingchun Wang ${ }^{1,2}$ and Wenli Chen ${ }^{1,2, *}$ \\ 1 MOE Key Laboratory of Laser Life Science \& Institute of Laser Life Science, South China Normal University, \\ Guangzhou 510631, China \\ 2 College of Biophotonics, South China Normal University, Guangzhou 510631, China \\ 3 Department of Experimental Plant Biology, Faculty of Science, Charles University, 12844 Prague, \\ Czech Republic \\ * Correspondence: chenwl@scnu.edu.cn; Tel.: +86-20-8521-1436-8611
}

Received: 5 July 2019; Accepted: 26 August 2019; Published: 27 August 2019

\begin{abstract}
Damaged or unwanted cellular proteins are degraded by either autophagy or the ubiquitin/proteasome pathway. In Arabidopsis thaliana, sensing of D-glucose is achieved by the heterotrimeric G protein complex and regulator of G-protein signaling 1 (AtRGS1). Here, we showed that starvation increases proteasome-independent AtRGS1 degradation, and it is correlated with increased autophagic flux. RGS1 promoted the production of autophagosomes and autophagic flux; RGS1-yellow fluorescent protein (YFP) was surrounded by vacuolar dye FM4-64 (red fluorescence). RGS1 and autophagosomes co-localized in the root cells of Arabidopsis and BY-2 cells. We demonstrated that the autophagosome marker ATG8a interacts with AtRGS1 and its shorter form with truncation of the seven transmembrane and RGS1 domains in planta. Altogether, our data indicated the correlation of autophagosome formation with degradation and endocytosis of AtRGS1 through ATG8a.
\end{abstract}

Keywords: Arabidopsis; regulator of G signaling protein 1; autophagy; nutrient starvation; glucose; BY-2

\section{Introduction}

Degradation of proteins in eukaryotic cells is mediated either through autophagy or the ubiquitin proteasome system (UPS). The UPS clears short-lived proteins, whereas autophagy degrades whole organelles and individual proteins that cannot be processed by the UPS [1]. Autophagy is a ubiquitous and highly conserved process, in which degrading misfolded and long-lived proteins, and damaged or old organelles are engulfed with a double membrane and then infused to the vesicle for lysosomal degradation, (or vacuole in plant cell). Stresses including starvation and oxidation, or stimulation by glucose and hormones accelerate autophagy processes [2-5]. Autophagic activity is low and balanced when cells contain sufficient nutrients, but increases rapidly when cells are starved. Cells survive starvation by recycling fatty acids and amino acids to meet the energy demand, and remove misfolded proteins and abnormal organelles [6]. The basic autophagy process is conserved among eukaryotes from yeast to animals and plants [7-9]. Several types of autophagy, including microautophagy [10], macroautophagy [9], chaperone-mediated autophagy [11], and organelle-specific autophagy, have been described in species [12]. Cell autophagy is normally maintained at a relatively low level, but increases abruptly when facing a disturbance. Autophagy preserves cell homeostasis and is one of the crucial safeguards of eukaryotic organisms.

The best indicator for autophagy is the formation of autophagosomes or double membrane vesicles that sequester other organelles or proteins. As the UPS and autophagy are both vital for 
cellular homeostasis (amino acids and fatty acid recycling, ATP economy), their activities are accurately orchestrated and regulated [1]. Improper autophagy is associated with pathologies, such as altered cell growth and cell death [12,13]. Sugars are common sources of energy and carbon supply [14]. Glucose functions as both a nutrient and a potent signaling molecule for controlling growth and development in eukaryotes [14,15]. Glucose signaling in Arabidopsis is integrated with pathways including the hexokinase 1 and G-protein signaling and glycolysis-dependent pathways [16]. Our previous paper showed that autophagy-related gene expression was induced by $1 \%$ glucose in wild-type (WT) Arabidopsis Col-0, but not in rgs1 mutant plants [3], indicating that RGS1 promoted autophagy-related gene mRNA is induced by glucose. It has been proposed that Heterotrimeric $G$ protein complex and regulator of G-protein signaling 1 (AtRGS1) is a glucose receptor or co-receptor in G-protein-mediated glucose sensing [17-19]. AtRGS1 is a GTPase activating protein (GAP) that acts on the G subunit of the heterotrimeric G protein complex. The molecule of Arabidopsis RGS1 includes an N-terminal seven transmembrane (7TM) domain fused with a cytoplasmic RGS domain [17-19]. AtRGS1 is a member of a glucose-sensing complex in Arabidopsis thaliana [20]. D-Glucose regulates AtRGS1 activity by interacting with $G$ protein alpha subunit $[17,19]$. When AtRGS1 is associated with GPA1, it turns off signaling by reducing the level of GTP-bound form of the G protein or through its GAP activity. Removal of bound glucose from the $G$ protein complex activates the G-protein signaling pathway as the Arabidopsis G subunit spontaneously binds GTP without requiring a guanine nucleotide exchange factor, such as the G-protein coupled receptor in animals [21,22].

The turnover of RGS1 protein in heterotrimeric G-protein signaling is important for numerous processes, including cell cycle regulation and cellular signaling. Study of the autophagy role in RGS1 homeostasis and glucose-induced metabolism will uncover the signaling/metabolic pathways involved in these processes and whether RGS1 is involved in autophagosome formation. In this study, we showed that nutrient starvation increases proteasome-independent AtRGS1 degradation, which is correlated with increased autophagic flux. Co-localization of RGS1 and autophagosomes was observed in Arabidopsis root cells and BY-2 cells. Glucose treatment induced autophagosome formation at early stages. RGS1 and its truncations can interact with the autophagosome marker ATG8a. This study demonstrates for the first time that the autophagosome participates in RGS1 metabolism in plants and that ATG8a co-localizes and interacts with RGS1 and its 7TM.

\section{Results}

\subsection{Glucose Decreased Autophagic Flux and Increased Formation of Autophagosomes in Plant Cells}

We first measured the formation of autophagosomes by induction with glucose [3]. As shown in (Figure 1A,D) cells supplied with the nutrients contained fewer autophagosomes, and the majority of the green fluorescent protein (GFP)-tagged autophagic marker ATG8a [23,24] were distributed evenly in the cytoplasm. Concanamycin A (CA) is an inhibitor of the vacuolar type $\mathrm{H}^{+}$-ATPase that has been used to inhibit degradation by reducing the activity of vacuoles to stabilize autophagic cargos [25,26], as in the observed autophagosome addition. Nutrient starvation increased the amount of autophagosomes in root cells (Figure 1B,D). Glucose increased the formation of autophagosomes in plant cells (Figure 1C,D), suggesting that starvation and glucose treatment induced autophagosome formation.

In addition, we measured the level of autophagic flux in plants as this determines the entire process of autophagy, including autophagosome formation, fusion with vacuoles and consequent breakdown, and the liberation of amino acids and fatty acids to the cytosol [27-29]. GFP-ATG8/light chain 3 (LC3) is the standard marker for autophagic flux, which is monitored by the release of its GFP tag [30,31]. An increase in autophagosomes in the cell is due to suppression of autophagosome maturation or increase in autophagic flux $[27,28]$. Consequently, quantitating autophagic flux is critical when analyzing the levels of key signaling molecules, such as AtRGS1 in this case. Therefore, we quantified the delivered amount of autophagy reporter, rather than relying solely on the autophagosome number. 
Autophagic flux, as measured by the release of GFP from GFP-ATG8a, was approximately 10-fold higher after starvation (Figure 1E). The 26S-proteasome inhibitor MG-115 that is known to increase autophagy [32] and the protein synthesis inhibitor cycloheximide that partially inhibits autophagy [33], were used to validate that this change was due to autophagy. Indeed, MG-115 increased flux and cycloheximide reduced flux (Figure 1E). When cells were re-fed with glucose, autophagic flux returned to a lower level within $3 \mathrm{~h}$ (Figure 1F).

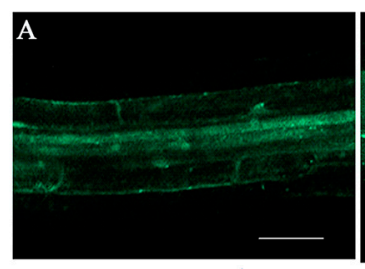

$\mathrm{E}$
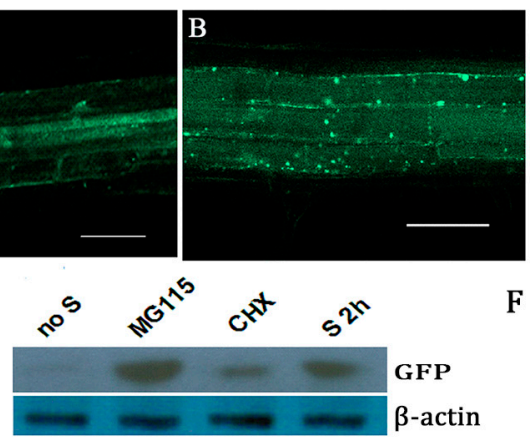

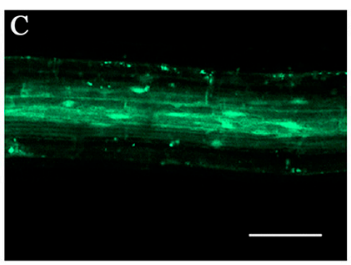

F

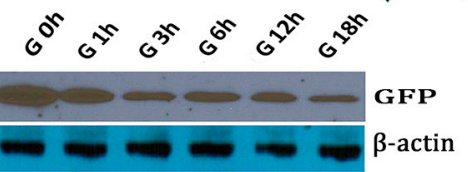

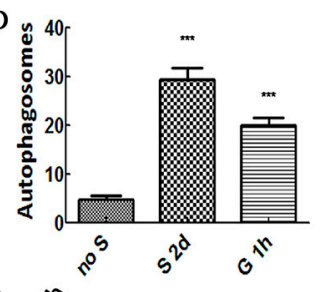
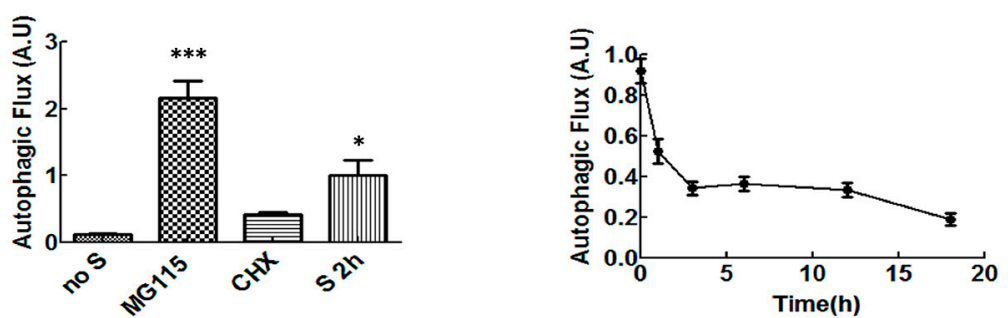

Figure 1. Proteasome-independent autophagosomes were induced by starvation and glucose. (A) Seven-day-old seedlings expressing GFP-ATG8a grown in $\frac{1}{2}$ MS medium containing $1 \%$ sucrose for 7 days. (B) Seven-day-old seedlings grown as described for panel A except for use of sucrose-free medium for 2 days. (C) Seven-day-old seedlings grown as described for panel A remove sucrose being transferred to media with added $2 \%$ glucose for $1 \mathrm{~h}$. Fluorescence from GFP-ATG8a visualized with a $488 \mathrm{~nm}$ excitation and 505-550 nm emission settings. A, B, C autophagosomes labeled by GFP-ATG8a in root cells incubation within $1 \mu \mathrm{M}$ CA for $12 \mathrm{~h}$. Scale bars $=50 \mu \mathrm{m}$. (D) Quantification of autophagosomes in root cells of four seedlings: "no S" means no starvation (A); "S 2d", starvation for 2 days (B); "G 1h", 2\% glucose treatment for $1 \mathrm{~h}$ (C). (E) Seven-day-old seedlings grown in liquid $\frac{1}{2}$ MS, and $1 \%$ sucrose under dim, continuous light. "Starved" indicates the seedlings treated with $\frac{1}{2}$ MS media without sucrose for $2 \mathrm{~h}$. Shown above is a typical Western blot probed with antiserum against GFP. Quantification of bands from replicate Western blots is shown below. MG-115, starvation plus $100 \mathrm{mM}$ MG115 for $2 \mathrm{~h} \mathrm{CHX,} \mathrm{starvation} \mathrm{plus} 70 \mu \mathrm{M} \mathrm{CHX}$ for $2 \mathrm{~h}$; "S 2 h", starvation with no sucrose for $2 \mathrm{~h}$ as control. (F) Glucose indicated by " $\mathrm{G}$ " was added at the indicated times. $\beta$-actin was used as loading controls. Each value was the mean \pm S.D. of four independent replicates. Asterisks indicate significant differences $\left({ }^{*} p<0.05\right.$ or $\left.{ }^{* * *} p<0.001\right)$.

\subsection{RGS1 Promoted the Production of Autophagic Flux and Autophagosomes}

To determine the relationship between RGS1 and autophagosome and autophagic flux, we performed screening by crossing rgs1 and GFP-ATG8a and obtained homozygous seeds containing GFP-ATG8a in rgs1. Autophagic flux was measured by Western blotting using GFP antibodies in rgs1 (GFP-ATG8a staining) transgenic Arabidopsis. As shown in (Figure 2A,B) in GFP-ATG8a, compared with the control, the content of free GFP was lower in $1 \%$ glucose treatment for 6 and $12 \mathrm{~h}$. In rgs1 (GFP-ATG8a staining), 1\% glucose treatment was performed separately for 0,6 and $12 \mathrm{~h}$, and no significant change was observed in free GFP expression, suggesting that RGS1 promotes the production of autophagic flux. We further investigated the root cells of GFP-ATG8a transgenic seedlings to observe whether autophagosomes were induced by $1 \%$ glucose treatment for $0.5 \mathrm{~h}$ in Arabidopsis thaliana. 
Therefore, the green punctate structures were examined using laser confocal scanning microscopy, before and after glucose treatment. Glucose led to dramatic changes, showing a significant increase in autophagosomes (Figure 2C,E). However, in 1\% glucose treatment for $0.5 \mathrm{~h}$ a small amount of autophagosomes were induced in rgs1 (GFP-ATG8a staining) (Figure 2D,E). These results indicate that RGS1 promotes the formation of autophagosomes.

A

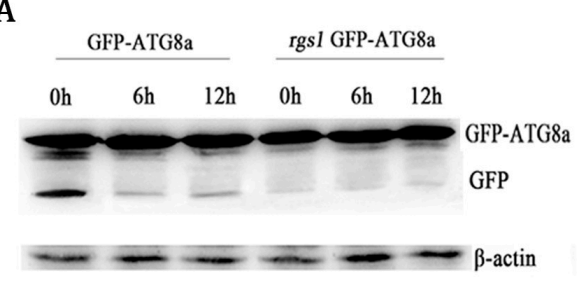

C

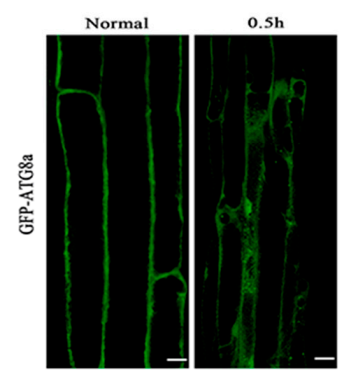

D

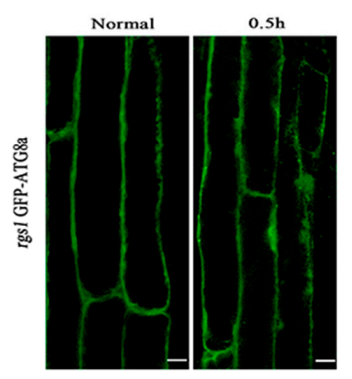

B

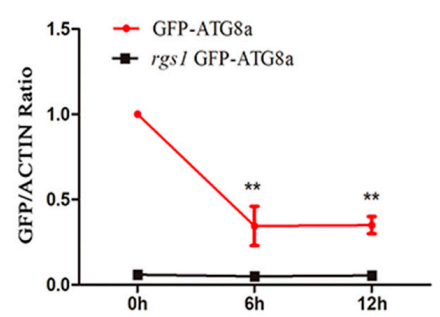

E

Figure 2. RGS1 promoted the production of autophagosomes and autophagic flux. Quantification of autophagic flux and GFP-ATG8a and rgs1 (GFP-ATG8a staining) seedlings. Seven-day-old seedlings of GFP-ATG8a treated by liquid MS medium without sugar following stimulation by $1 \%$ glucose for 0,6 , and $12 \mathrm{~h}$. (A) Equal amounts of protein extracted from the seedlings were used in SDS-PAGE, followed by Western blotting with anti-GFP and anti- $\beta$-actin antibodies. (B) Quantification of changes in free GFP normalized with the expression of $\beta$-actin. Asterisks indicate significant differences compared to starved seedlings treated with $1 \%$ glucose for $0 \mathrm{~h} * *<0.01$. Error bar represent S.D. obtained from three independent replicates. (C) Observation of autophagosomes. Autophagosomes labeled by GFP-ATG8a and rgs1 (GFP-ATG8a staining), in roots of GFP-ATG8a plants incubated with $1 \mu \mathrm{M} \mathrm{CA}$ for $12 \mathrm{~h}$. Normal seedlings and GFP-ATG8a in seedlings treated by $1 \%$ glucose for $0.5 \mathrm{~h}$ in GFP- ATG8a. (D) Normal seedlings and 1\% glucose seedlings for $0.5 \mathrm{~h}$ in $r g s 1$ (GFP-ATG8a staining) seedlings treated by $1 \%$ glucose for $0.5 \mathrm{~h}$. (E) Quantification of GFP-ATG8a and rgs1 (GFP-ATG8a staining), labeled autophagosomes per root cell at the indicated times were used to calculate autophagic activity. Mean and S.D. values were calculated from roots of six seedlings per time point. Results from three parallel experiments were used for quantification. Asterisks indicate significant differences of the starved seedlings treated with glucose from normal ones. Scale bars $=10 \mu \mathrm{m}\left({ }^{* *} p<0.01\right.$ or $\left.{ }^{* * *} p<0.001\right)$.

\subsection{RGS1 Degradation is Correlated with Increased Autophagic Flux Independent of the Proteasome}

Interestingly, we observed that the change in autophagic flux was due to degradation and re-feeding of RGS1 protein resulted in the opposite event. After starvation of sucrose for $2 \mathrm{~h}$, the steady-state level of AtRGS1 decreased, and autophagic flux increased (Figure 3A-C). Upon addition of glucose, the level of AtRGS1 recovered and autophagic flux returned to the baseline. Thus, alteration of RGS1 steady state levels was induced by nutrient starvation and addition of $1 \%$ glucose. The starvation-induced decrease of total AtRGS1 occurred in the presence of proteasome inhibitor MG-115 (Figure 3D,E), suggesting that the decrease in AtRGS1 results from autophagy and not by proteasome. As MG-115 itself induces autophagy, the addition of this inhibitor further decreased the steady-state level of AtRGS1 in comparison with nutrient starved conditions. To verify whether AtRGS1 vesicles can 
fuse with autophagosomes containing ATG8a, we designed the following experiments to show the co-localization of RGS1 and autophagosomes.

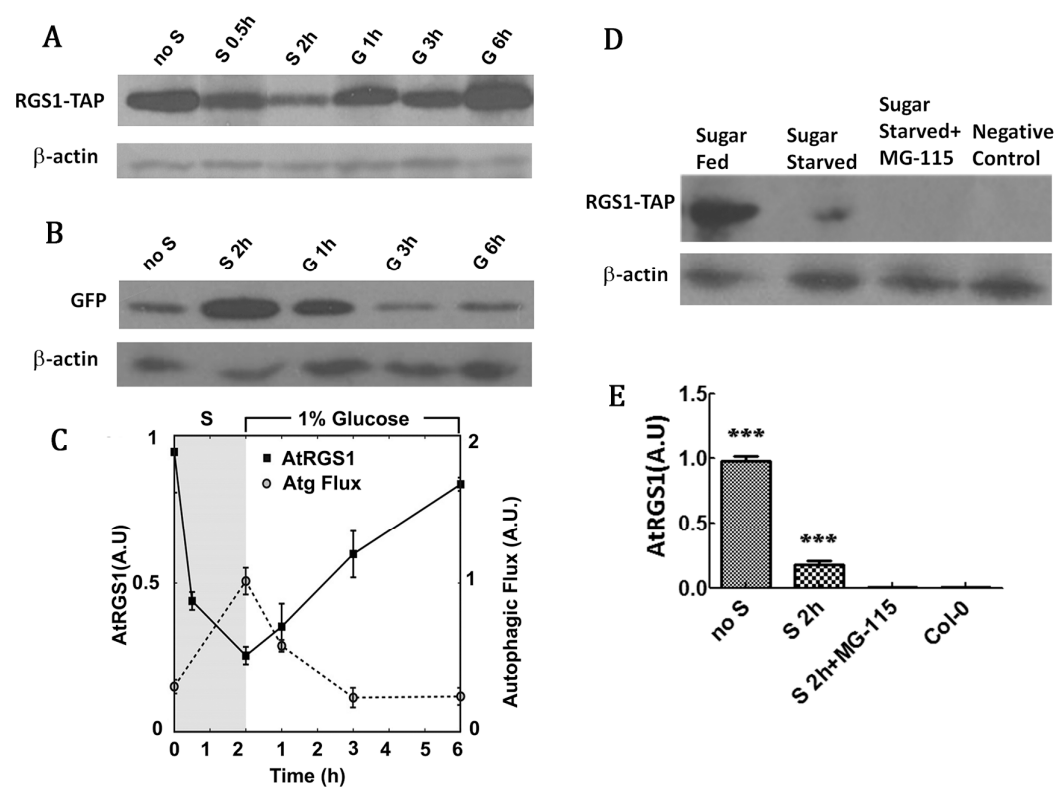

Figure 3. Levels of RGS1 and autophagic flux were observed during starvation and recovery. (A) TAP tagged AtRGS1. Seven-day-old seedlings were cultured in $\frac{1}{2}$ X MS $1 \%$ sucrose under dim, continuous light, and then transferred to media with no sucrose (no S, Starved) and treated with $1 \%$ glucose for 1, 3, and $6 \mathrm{~h}$ (G $1 \mathrm{~h}, \mathrm{G} 3 \mathrm{~h}$, and G $6 \mathrm{~h}$, respectively); Western blot was probed with PAP antibody. (B) Autophagic flux. Same as for A except the Western blot was probed with antiserum directed against GFP. (C) Quantitation of levels of AtRGS1-TAP and autophagic flux under starvation (S) or 1\% glucose for various hours. (D) Seedlings were treated as described in A except with MG115 (100 mM) treatment in liquid $\frac{1}{2}$ X MS or no MG115 for $2 \mathrm{~h}$. (E) Quantification of changes in D. Each value was the mean \pm S.D. of four independent replicates. $\beta$-actin was used as loading controls. Asterisks indicate significant differences $\left({ }^{* * *} p<0.001\right)$.

\subsection{Co-Localization of RGS1 and Autophagosomes}

Seedlings of GFP-ATG8a and RGS1-red fluorescent protein (RFP) were observed for colocalization of autophagosomes with RGS1 in Arabidopsis root cells. In comparison with the autophagosome formation and AtRGS1 under normal growth conditions (Figure 4A) (Figure S1), after half an hour post-treatment with $6 \%$ glucose of cells, autophagosomes and AtRGS1 were found to overlap (Figure 4B) (Figure S1), indicating their co-localization was internalized by glucose induced endocytosis.

BY-2 cells are relatively homogenous and are suitable for studies of autophagy [34,35]. LysoTracker Red (LTR) dye is an effective autophagosome stain used to quantitate autophagy activity [36-38], and it can slightly stain Nicotiana tobaccos RGS1 (NtRGS1) in cytoplasm especially on the plasma membrane. The results showed that the punctate fluorescent signal of GFP-tagged tobacco RGS1 (NtRGS1-GFP) overlapped with the LTR punctate signals, with an estimate of $\sim 35 \%$ co-localization of the two markers (Figure 4C) (Figure S2), whereas starvation increased co-localization to $70 \%$ (Figure 4D) (Figure S2). This finding is consistent with results obtained by Hanamata et al. using the autophagic flux marker yellow fluorescent protein (YFP)-tagged NtATG8a for autophagosome formation [35]. We found that autophagosomes were increased by $0.5 \mathrm{~h}$ sucrose treatment after 2 days starvation and that a portion of RGS1-GFP was located in LTR punctate signals (autophagosome), implying that parts of RGS1-GFP were recycled in autophagosomes.

Starvation of BY2 cells increased the NtRGS1-GFP punctate signals and specific punctate structures stained with LTR (Figure 4D). The increased co-localization suggests that starvation drives NtRGS1 into the autophagosome. Our BY-2 cellular experiment showed the significant increase in autophagosome 
after 3\% sucrose treatment (Figure 4E), consistent with induction of autophagosomes in Arabidopsis by glucose (Figure 1C). We observed that NtRGS1 ${ }^{1-248}$-GFP, NtRGS1 ${ }^{249-413}$-GFP, and NtRGS1 ${ }^{249-459}$-GFP in BY-2 cells overlapped with LTR punctate signals (Figure 5), suggesting that co-localization of NtRGS1 truncations and autophagosomes occurred by $0.5 \mathrm{~h}$ sucrose induction.

FM4-64 dye is widely used in the study of plasma membrane and vesicles; it combines with plasma membrane and endometrial organelles to produce high-intensity fluorescence. This dye is used for the observation of autophagosomes, such as in tobacco cells, under sucrose starvation treatment, the flow of plasma membrane to the autophagosome membrane was observed by FM4-64 dye, and the central vacuole component was autophagosome, indicating that endocytosis and supply from central vacuoles may aid in the formation of autophagosomes [39]. Related studies have shown that accumulation of autophagosomes in Arabidopsis root cells and yeast cells can be detected using FM4-64 [40,41]. Here, we observed the confocal of Arabidopsis thaliana root cells treated with 3\% glucose and stained with FM4-64 dye. The results of the FM4-64 dye encapsulating the yellow fluorescent RGS1-YFP illustrates the close relationship between autophagy and RGS1 (Supplementary Video).
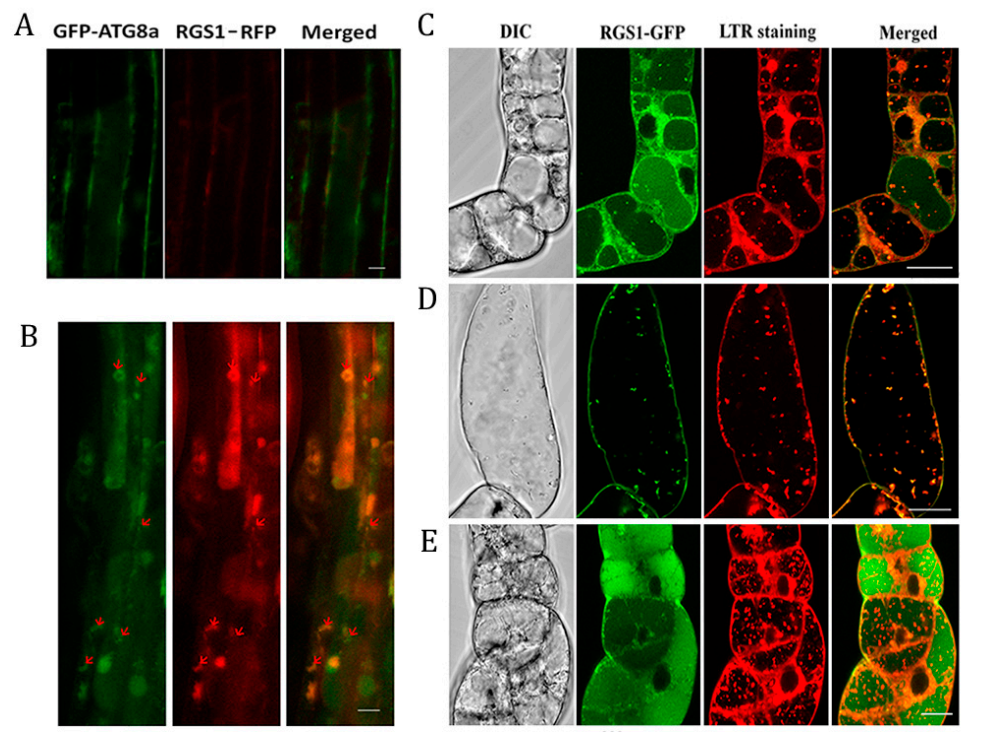

Figure 4. Co-localization of RGS1 and autophagosomes was detected in Arabidopsis root cells and BY-2 cells. (A) Absence of endocytosis of AtRGS1 with RGS1-RFP/GFP-ATG8a seedlings under normal growth conditions ( $\frac{1}{2}$ MS medium containing $1 \%$ sucrose for 7 days) was observed. (B) Endocytosis of AtRGS1-RFP remove sucrose being transferred to media with added $\%$ glucose for $1 \mathrm{~h}$ by GFP-ATG8a, and showing co-localization of GFP-ATG8a and AtRGS1-RFP. (A) and (B) Scale bar $=10 \mu \mathrm{m}$. GFP-tagged Nicotiana tabacum NtRGS1 (C) under MS 3\% sucrose treatment for 5 days, and added with $1 \mu \mathrm{M} \mathrm{CA}$ $12 \mathrm{~h}$ (control). (D) RGS1 with MS 3\% sucrose treatment for 3 days, starvation for 2 days, and added with $0.5 \mu \mathrm{M}$ CA for $12 \mathrm{~h}$ (starvation). (E) RGS1 with MS 3\% sucrose treatment for 3 days, starvation (MS, no sucrose) for 2 days, and $3 \%$ sucrose restoration for $0.5 \mathrm{~h}$, showing numerous autophagosomes. Differential contrast microscopy (DIC), merged image of green (or yellow) and red. NtRGS1-GFP BY-2 cells were standardly cultured for 3 days, and then supplemented with $3 \%$ sucrose (control) or without sucrose (starvation). Con A $(1 \mu \mathrm{M})$ and LTR stain were added for confocal imaging. LTR fluorescence appeared red, and RGS1-GFP appeared green. In the merged images, the overlap of LTR and RGS1 fluorescence appeared yellow. (C) (D) (E) Scale bar $=20 \mu \mathrm{m}$. Autophagosomes stained with LTR.

\subsection{ATG8a Interacts with Full-Length and Truncated RGS1}

Our previous paper showed that ATG2 and ATG5 inhibited AtRGS1 recovery after D-glucose treatment, whereas 1\% glucose treatment induced ATG gene expression [3]. Both ATG2 and ATG5 play important roles in autophagosome formation [3,42]. AtRGS1-YFP is located on the plasma membrane in WT and atg2 and atg 5 mutant plants (Figure 6A,D). After addition of $6 \%$ glucose for 0.5 
h, autophagy inhibitor 3-methyladenine (3-MA) affected the subcellular localization of AtRGS1-YFP (Figure 6B,E), as shown by an increase in AtRGS1-YFP vesicles. This result suggests the internal location of AtRGS1-YFP in the plasma membrane. In the absence of 3-MA, the number of AtRGS1-YFP vesicle was reduced in atg 2 and atg5 mutants compared with the WT (Figure 6C,F), implying that sequestration of autophagy-related proteins (at least ATG2 and ATG5) participates in AtRGS1 metabolism. As AtRGS1 endocytosis is a type of stimulation, we would assume that ATG2 and ATG5 might provoke the stimulation of RGS1 endocytosis. To further confirm that the autophagosome marker GFP-ATG8a interacts with RGS1 and its truncations, we carried out bimolecular fluorescence complementation (BiFC) and pull-down experiments.

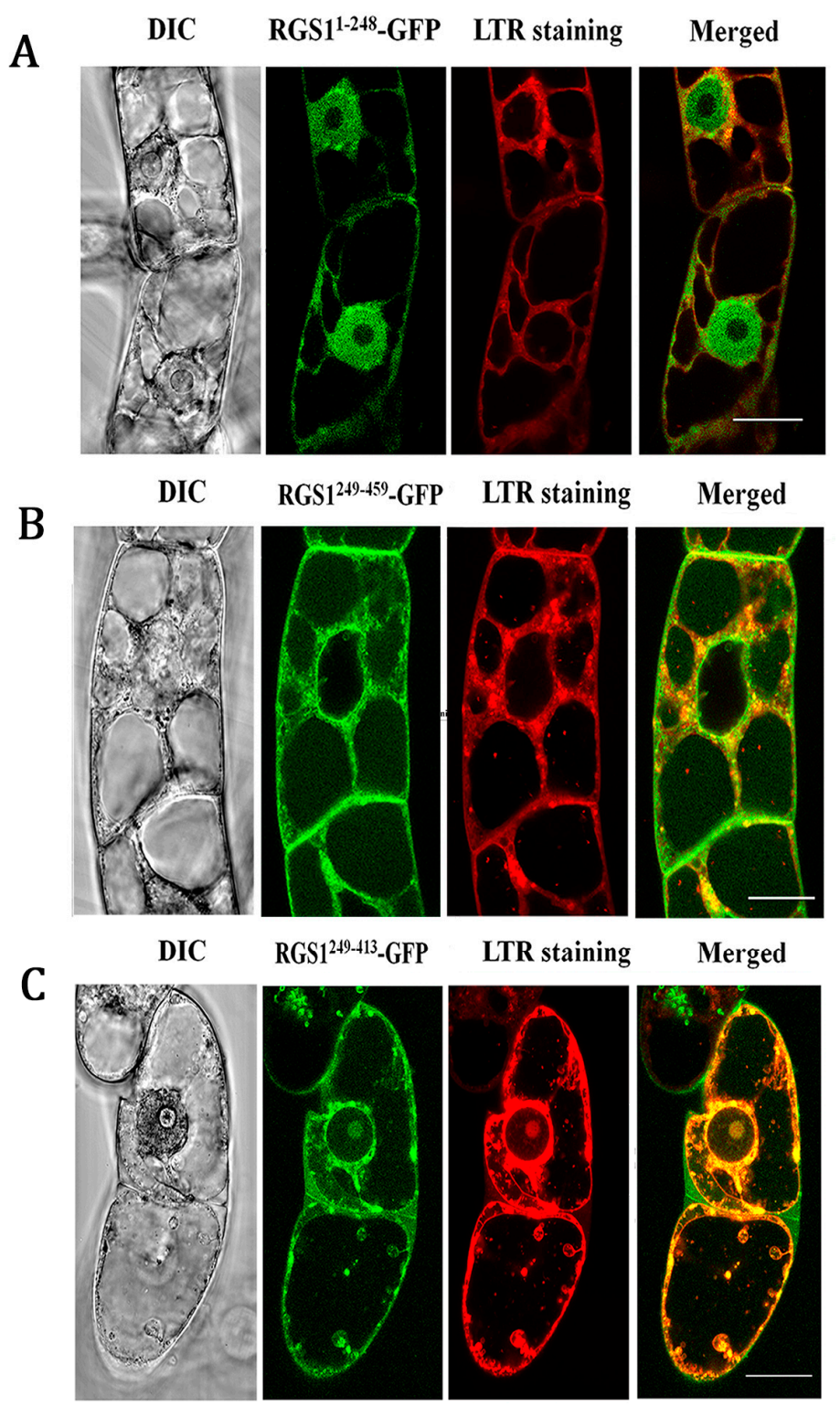

Figure 5. Co-localization of NtRGS ${ }^{11-248}$-GFP, NtRGS ${ }^{1249-459}-\mathrm{GFP}, \mathrm{NtRGS}{ }^{1249-413}$-GFP and autophagosomes was observed in BY-2 cells. (A) BY-2 cells expressing GFP-tagged Nicotiana tabacum $N t R G S 1^{1-248}$, (B) NtRGS1 $1^{249-459}$, and (C) NtRGS1 ${ }^{249-4^{\prime} 13}$. BY-2 cells were grown under normal conditions (MS 3\% sucrose) for 7 days, with $1 \mu \mathrm{M}$ (final concentration) CA added for $12 \mathrm{~h}$, and $3 \%$ sucrose was re-added for $0.5 \mathrm{~h}$. DIC, LTR fluorescence appeared red, RGS1-GFP gives green, and the merged images of LTR and RGS1 fluorescence presented a yellow color. Scale bar $=20 \mu \mathrm{m}$. Four independent replicates. 
A

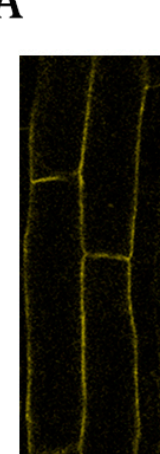

MS culture

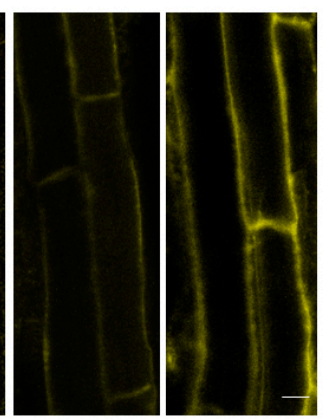

WT

D

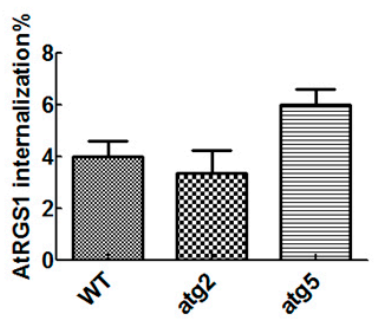

B

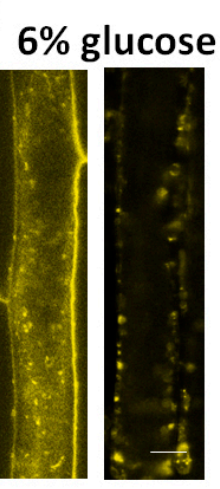

$+3-\mathrm{MA}$

E

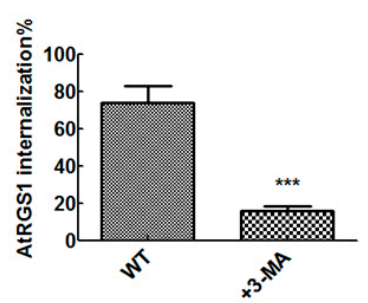

C

$6 \%$ glucose
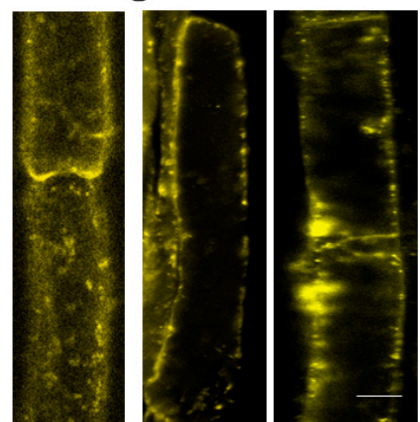

WT atg2 atg5

F

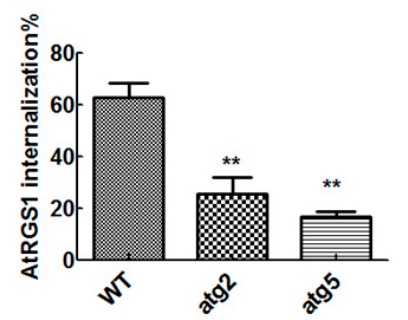

\section{G}

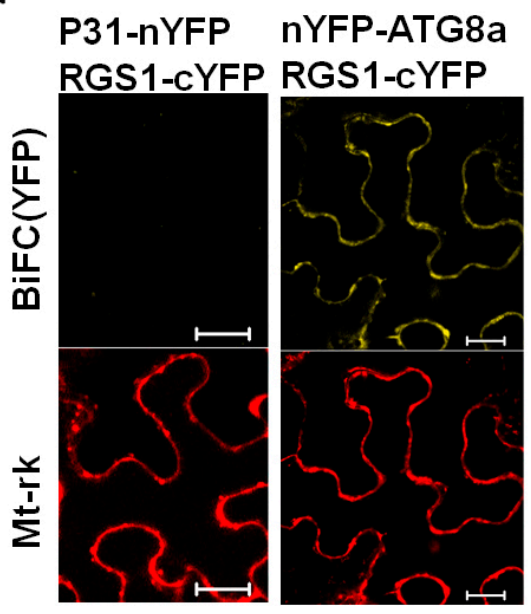

Figure 6. AtRGS1-YFP endocytosis was limited in atg2 and atg5, AtRGS1 interacted with ATG8a in vivo. (A) Location of WT, atg2, and atg5 AtRGS1-YFP in the plasma membrane under normal growth conditions ( $\frac{1}{2}$ MS medium containing $1 \%$ sucrose for 7 days). (B) Endocytosis of AtRGS1-YFP remove sucrose being transferred to media with added $6 \%$ glucose and was inhibited by autophagy inhibitor 3-MA. (C) Comparison with the endocytosis of AtRGS1-YFP in Columbia ecotype induced by removing sucrose being transferred to media with added $6 \%$ glucose for $0.5 \mathrm{~h}$, which was inhibited in atg 2 and atg5. Image obtained with confocal microscopy for AtRGS1 internalization amount (see Materials and Methods). (D) Quantification of changes in A. (E) Quantification of changes in B. (F) Quantification of changes in C. (G) BiFC was used to test the physical interaction between test proteins. Tobacco pavement cells were co-transformed with the indicated BiFC pairs plus an internal positive transformation control Mt-rk. Transformation was performed as described in Methods. Images were captured on the third day of cell growth and the presented data are the lowest detectable level of expression to avoid ectopic complementation of fluorescence. The RGS1-YFP band is indicated. Scale bar $=20 \mu \mathrm{m}$. Each value is the mean \pm S.D. of four independent replicates. Asterisks indicate significant differences $(* * p<0.01$ or $* * * p<0.001)$. 
In the BiFC experiment (Figure 6G), fluorescence was complemented in the cells expressing AtRGS1-cYFP, which was tagged with the autophagy protein nYFP-ATG8a, but not in cells expressing the negative control P31-nYFP. ATG8 is a ubiquitin-like protein involved in cargo recruitment and biogenesis of autophagosomes. Autophagosome size is determined by the amount of ATG8. As ATG8 is selectively enclosed by autophagosomes, its breakdown would allow measurement of the autophagic rate [30].

To verify the interaction of ATG8a with RGS1 and its truncations, we used purified protein His-ATG8a to pull down RGS1 and its truncations, which were expressed in Nicotiana benthamiana leaves by Agrobacterium infiltration. ATG8a pulled down RGS1 and its truncations including RGS1-GFP, GFP, RGS1 ${ }^{1-283}, \mathrm{RGS1}^{1-413}$, RGS1 ${ }^{1-283,414-459}, \mathrm{RGS1}^{1-250}$, and RGS1 ${ }^{14-250}$ (Figure 7), indicating that both RGS1 7TM and RGS1 domains interact with ATG8a. Altogether, our data demonstrate that the autophagosome is closely related to RGS1.

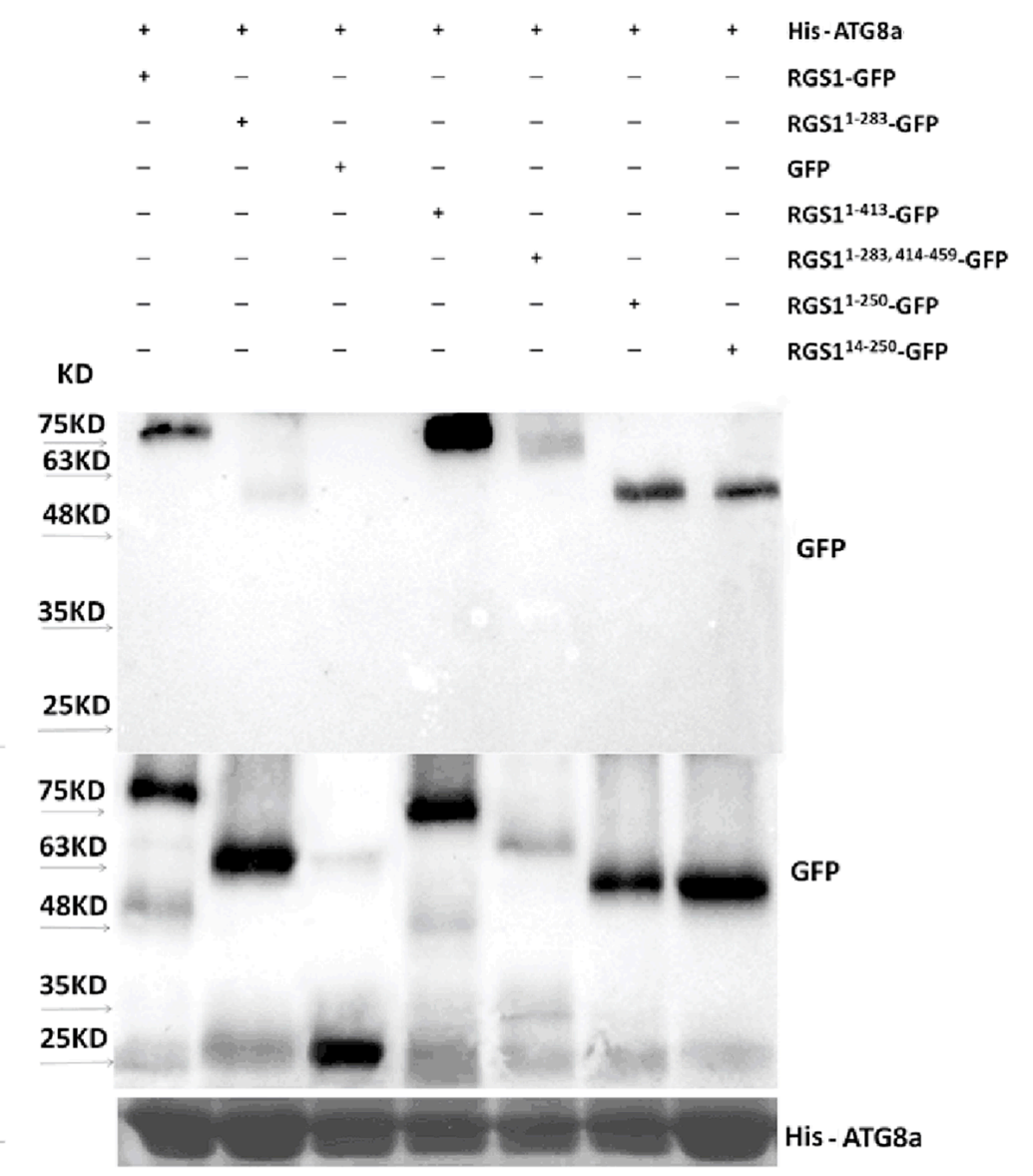

Figure 7. Pull down assay of RGS1 and its truncations by His-tagged ATG8a was performed. Proteins of RGS1-GFP, RGS1 1-283 _GFP, GFP, RGS1 ${ }^{1-413}$ _GFP, RGS1 ${ }^{1-283,414-459}$ _GFP, RGS1 ${ }^{1-250}$ _GFP, RGS1 ${ }^{14-250}$-GFP, were purified by His-ATG8a on Ni-NTA agarose column and detected by Western blotting using the GFP antibody (see Materials and Methods).

\section{Discussion}

Throughout the eukaryotic kingdom, RGS proteins act as negative regulators in G protein signaling. In animal cells, RGS proteins participate in cellular processes, including cell growth, mitosis, neuron signaling, membrane diffusion, embryo development, and inflammatory and neurodegenerative diseases [20,43-45]. In humans and nematodes, RGS proteins are involved in almost all signaling transmission and adjustment processes. AtRGS1 serves as an important sensor for glucose in 
Arabidopsis $[19,20]$. The study of the relationship between plant cell autophagy and RGS1 is instrumental to our understanding of the role of RGS1 in sugar signaling.

Our study showed the metabolism of RGS1 is negatively correlated with autophagic flux (Figure 3A,C). Autophagic flux and autophagosomes of rgs1 mutant express all rarely processing at different times. (Figure 2). In addition, we noted that in co-localization of AtRGS1 and ATG8a after glucose-induced (Figure 4B) co-localization of NtRGS1 and autophagosomes (with LTR stain) under normal conditions, starvation treatment and sucrose recovery (Figure 4C-E), the rate of co-localization under starvation treatment was higher than that under normal conditions, that is, sucrose induced more autophagosomes (Figure 4C,E). We further confirmed that ATG8a can interact with RGS1 and its truncations (Figure 7). FM4-64 as a marker of endocytosis is able to trace the formation of autophagosomes, with RGS1-YFP being wrapped by this dye (Supplementary Video). These results suggest that autophagy may participate in RGS1 degradation during starvation and RGS1 endocytosis by inducement with glucose. Autophagosomes are induced by treatment with glucose (Figure 1C,D) and sucrose (Figure 4E) at the early phase stage. We speculate that exuberant metabolism may be associated with increased autophagosomes. Xiong et al. observed that $30 \mathrm{mM}$ (about $0.54 \%$ ) glucose treatment inhibited autophagy through inducing activity of protein kinase target of rapamycin (TOR) [46]. RGS1 promotes ATG expression after glucose induction [3]. Our results show that 1-6\% glucose treatment in the early phase promoted autophagosome formation (Figure 1C) and negatively regulated autophagic flux in Arabidopsis (Figure 2B). The 3\% sucrose treatment induced the production of autophagosomes in BY2 cells after starvation (Figure 4E). We used mannitol as a control treatment and observed that autophagosomes treated by $3 \%$ glucose were induced by glucose rather than osmotic stress (Figure S3).

\section{Materials and Methods}

\subsection{Plant Materials and Growth Conditions}

All Arabidopsis lines were of the Columbia ecotype. Seed surface was sterilized with 70\% ethanol for $10 \mathrm{~min}, 95 \%$ ethanol for $10 \mathrm{~min}$, and finally washed with water. Seeds were vernalized at $4{ }^{\circ} \mathrm{C}$ for 2 days in $\frac{1}{2}$ X Murashige and Skoog (MS) liquid medium supplemented with $1 \%$ sucrose. A total of 100 Arabidopsis seed were grown in $100 \mathrm{~mL}$ liquid medium in a $250 \mathrm{~mL}$ flask with rotary shaking at $140 \mathrm{RPM}$ under dim continuous light $\left(40 \mu \mathrm{E} \mathrm{m} \mathrm{m}^{-2} \cdot \mathrm{s}^{-1}\right)$ at $23^{\circ} \mathrm{C}$ for 7 days.

After sterile rinsing thrice with water and starvation using $\frac{1}{2}$ MS lacking sucrose for $2 \mathrm{~h}$, the seedlings were transferred to $\frac{1}{2}$ MS with $100 \mathrm{mM}$ MG115 or $70 \mu \mathrm{M}$ CHX in continuous dim light for $6 \mathrm{~h}$, whereas the same medium with $1 \%$ glucose was used as control. All experiments were performed at least thrice. For immunoblot analyses, seedlings were harvested and flash frozen in liquid nitrogen.

WT Nicotiana benthamiana plants were used for BiFC and pull-down experiments. Plants were grown at $23^{\circ} \mathrm{C}$ and $70 \%$ relative humidity under a $16 \mathrm{~h}$ light $/ 8 \mathrm{~h}$ dark cycle for $1-1.5$ months before infiltration. After infiltration, plants were kept under the same growth conditions.

\subsection{Arabidopsis Thaliana Mutants and Transgenic Lines}

atg2 (SALK_076727), and atg5 (SALK_020601) were obtained from the Arabidopsis Biological Resource Center. AtRGS1 (encoding amino acids 1-459) was subcloned to pEarleyGate205 (C-terminal TAP). The 35S::AtRGS1-YFP construct was transformed into Agrobacterium EHA105, which was then used to transform WT, atg2, and atg 5 by the floral-dip method [47], homozygous lines of transgenic plants were used in this study.

The coding regions of RGS1 were amplified with TaKaRa Ex Taq DNA Polymerase (Fisher Scientific, R001A) using specific primers containing Gateway attB sites and then cloned into pDONR207 (Figure S4) entry vector using the BP Clonase II (Life Technologies) to create RGS1 entry clones. After verification by sequencing, each clone was mobilized using the LR Clonase II (Life Technologies) into the Gateway destination vector pK7RWG2 (Figure S5). The primers used for pENTR clones 
in autophagy-related gene. The 35S::AtRGS1-RFP construct were transformed into Agrobacterium EHA105, which was then used to transform the transgenic Arabidopsis expressing GFP-ATG8a (Dr. Faqiang Li providing) by the floral-dip method [47]; homozygous line RGS1-RFP/GFP-ATG8a of transgenic plants was used in this study (Figure S1A).

Homozygous rgs1 (GFP-ATG8a staining) was successfully crossed through crossing rgs1 and GFP-ATG8a. In general, first cross rgs1 and GFP-ATG8a and the next generation were screened in Basta-resistant medium to confirm the cross success ( $r g s 1$ is a hybrid, confocal observation was performed to select the strong seedlings and transfer them to the soil, and obtain seeds). Then, the materials collected from each plant were grown on $10 \mu \mathrm{g} / \mathrm{mL}$ Basta-resistant medium and the seedlings on all the grown plates were selected. Confocal observation confirmed a relatively strong GFP fluorescence, the seedlings were transferred to the soil, and each strain was confirmed to be a rgs1 mutant (Figure S6). In theory, the seedlings were homozygous rgs1 (stain GFP-ATG8a), and the next generation confirmed rgs1 (stain GFP-ATG8a) as homozygous.

\subsection{AtRGS1-YFP Internalization Analysis}

Fluorescence quantification for AtRGS1-YFP internalization was performed as described by Urano et al. [48] and Fu et al. [49]. WT, atg2, and atg5 seedlings (7 days old) were treated with $0 \%$ or $6 \%$ D-glucose $(w / v)$ for $30 \mathrm{~min}$. Root epidermal cells located 2-4 mm below the cotyledon were imaged (Z stacks obtained) using a Zeiss LSM710 confocal laser scanning microscope equipped with a $20 \times$ Plan-NeoFluor numerical aperture (N.A. $=0.5)$ objective and a $40 \times$ C-Apochromat (N.A. $=$ 1.2) water immersion objective. YFP fluorescence was excited by a $514 \mathrm{~nm}$ argon laser and detected at 526-569 $\mathrm{nm}$ by a photomultiplier detector. At least 10 sets of images from seven seedlings were obtained for internalization quantification analysis by Image software.

\subsection{BiFC}

BiFC was pe work of Klopffleisch et al. [50]. The coding regions of ATG8a were amplified with TaKaRa Ex Taq DNA Polymerase (Fisher Scientific, RR001A, Invitrogen, Waltham, MA, USA) using specific primers containing Gateway attB sites and then cloned into the pDONR207 entry vector (Figure S4) using the BP Clonase II (rformed as described in the Life Technologies, Invitrogen) to create ATG8a entry clones. After verification by sequencing, each clone was mobilized using the LR Clonase II (Life Technologies) into the Gateway destination vector pCL112_JO (Figure S7) for BiFC. The primers used for pENTR clones in autophagy-related gene ATG8a are listed as follows: GGGGACAAGTTTGTACAAAAAAGCAGGCTTCATGATCTTTGCTTGCTTGAAATT and GGGGACCACTTTGTACAAGAAACTGGGTCTCAAGCAACGGTAAGAGATCCAAAAGT. The open reading frame of AtRGS1 in BiFC vectors was as previously described by Grigston et al. [51].

Agrobacterium tumefaciens strain EHA105 was cultured on Luria Bertani (LB) medium for 2 days, and a single colony was inoculated into $5 \mathrm{~mL}$ LB medium supplemented with the appropriate antibiotics (spectinomycin) and grown at $28^{\circ} \mathrm{C}$ in a shaker for $48 \mathrm{~h}$. The culture was transferred to the infiltration buffer with $10 \mathrm{mM}$ 2-( $\mathrm{N}$-morpholine)-ethanesulfonic acid (MES; pH 5.6) and $40 \mu \mathrm{M}$ acetosyringone $(1: 100$ ratio, $v / v)$ for growth at $28{ }^{\circ} \mathrm{C}$ for $16 \mathrm{~h}$. When growth reached $\mathrm{A}_{600}=3.0$, the bacteria were spun down gently $(3200 \mathrm{~g}, 10 \mathrm{~min}$ ), and the pellets were resuspended in $10 \mathrm{mM} \mathrm{MgCl} 2$ at a final $\mathrm{A}_{600}=1.5\left(\mathrm{~A}_{600}=1\right.$ for $\left.\mathrm{p} 19\right)$. A final $150 \mu \mathrm{M}$ acetosyringone was added and the bacteria were kept at room temperature for at least $4 \mathrm{~h}$ without shaking.

Split nYFP- and cYFP-tagged protein pairs (nYFP-ATG8a and RGS1-cYFP; P31-nYFP and RGS1-cYFP), p19 (gene silencing suppressor), and mitochondrial RFP marker (Mt-rk, an internal transformation control) were co-expressed in 4-5-week-old Nicotiana benthamiana leaves by Agrobacterium tumifaciens-mediated infection. Leaf infiltration was conducted by fully depressing a $1 \mathrm{~mL}$ suspension with a syringe onto the surface of leaves. Infiltrated leaves exhibited a water-soaked appearance. Images were captured 3 days after inoculation. 
Leaf disks were obtained from infiltration sites and imaged by confocal microscopy as previously described [48]. Tobacco leaf epidermal cells were imaged using a Zeiss LSM710 confocal laser scanning microscope equipped with an Apochromat 40x water immersion objective (N.A. $=1.2$ ). YFP fluorescence was excited by a $514 \mathrm{~nm}$ argon laser and detected at $526-569 \mathrm{~nm}$ by a photomultiplier detector, and Mt-rk and RFP fluorescence was excited by a $543 \mathrm{~nm}$ HeNe laser and detected at $565-621 \mathrm{~nm}$.

\subsection{Transformation of BY-2 Cells}

BY-2 cells (Nicotiana tabacum "Bright Yellow") were cultured in modified MS medium supplemented with $3 \%(w / v)$ sucrose, $1 \mu \mathrm{g} / \mathrm{mL}$ thiamine- $\mathrm{HCl}, 0.2 \mu \mathrm{g} / \mathrm{mL} 2,4-\mathrm{D}, 100 \mu \mathrm{g} / \mathrm{mL}$ myo-inositol, and $200 \mu \mathrm{g} / \mathrm{mL}$ $\mathrm{KH}_{2} \mathrm{PO}_{4}$, with a final $\mathrm{pH} 5.8$ adjusted by $\mathrm{KOH}$. Cell lines were cultured in either liquid MS medium with continuous shaking, or in the form of calli on MS media solidified with $0.8 \%(w / v)$ agar in the dark at $26{ }^{\circ} \mathrm{C}$. Suspensions were sub-cultured every 7 days by transferring $1.5 \mathrm{~mL}$ culture into $30 \mathrm{~mL}$ fresh MS medium; calli were sub-cultured every 3-4 weeks. NtRGS1 was expressed under 35S promoter in our constructs. The tobacco homolog of AtRGS1, the NtRGS1 gene was amplified from BY-2 cDNA and cloned into pDrive cloning vector with $12 \mathrm{bp}$ of Kozak sequence to achieve seamLess expression. The fragment was subsequently cloned into the pGreen binary vector using BamHI and HindIII to create C-terminal fusion with enhanced GFP. Partial digestion was required for this procedure.

Transformation of BY-2 cells was performed using Agrobacterium tumefaciens carrying the binary vector pCP60 harboring NtRGS1 ${ }^{1-459}$-GFP, NtRGS1 ${ }^{1-248}$-GFP, and NtRGS1 ${ }^{249-413}$-GFP, NtRGS1 ${ }^{249-459}$-GFP [34,52]. The primers were as follows: GGAGAATAAATTATGGCAGCTTG and GCAGTTTTGAATCATGACTATGG GFP-tagged Nicotiana tabacum NtRGS1 ${ }^{1-459}$-GFP, NtRGS1 ${ }^{1-248}$, NtRGS1 ${ }^{249-459}$, and NtRGS1 ${ }^{249-413}$, see Domain structure of the RGS1 protein in Figure S8.

Exponential cell suspension (3-4 days after sub-culturing) was filtered and resuspended in $30 \mathrm{~mL}$ of fresh MS medium. Acetosyringone $(15 \mathrm{~mL}, 40 \mathrm{mM})$ was added to the suspension and thoroughly mixed by pipetting. Total of $3 \mathrm{~mL}$ Agrobacterium suspension was then added to the cell suspension and cultivated for 3 days in the dark at $26^{\circ} \mathrm{C}$. The cells were washed with $300 \mathrm{~mL} 3 \%(w / v)$ sucrose and $100 \mathrm{~mL}$ MS medium supplemented with $100 \mathrm{mg} / \mathrm{L}$ cefotaxime. Finally, the cells were resuspended in 2-3 mL liquid MS medium containing $100 \mathrm{mg} / \mathrm{L}$ cefotaxime and $50 \mathrm{mg} / \mathrm{L}$ kanamycin and cultured in a Petri dish for $3-4$ weeks in the dark at $26^{\circ} \mathrm{C}$. The calli cultures were transferred onto fresh MS medium with the same antibiotics. Grown cells ( $3 \mathrm{~d}$ sub-culturing) were centrifuged at $5000 \mathrm{~g}$ for $10 \mathrm{~min}$, rinsed thrice with sucrose-free BY-2 medium and subsequently starved in MS medium for 2 days. BY-2 cells grown in the MS medium supplemented with 3\% sucrose served as control.

\subsection{Co-Localization of RGS1 and Autophagosome}

WT, atg2, and atg5 RGS1-RFP/GFP-ATG8a seedlings (7 days old) were treated with $0 \%$ or $6 \%$ D-glucose $(w / v)$ for $30 \mathrm{~min}$. Root epidermal cells located 2-4 mm below the cotyledon were imaged (Z stacks obtained) using a Zeiss LSM710 confocal laser scanning microscope equipped with a $20 \times$ Plan-NeoFluor (N.A. $=0.5$ ) objective and a $40 \times$ C-Apochromat (N.A. $=1.20$ ) water immersion objective. GFP fluorescence was excited by a $488 \mathrm{~nm}$ argon laser and detected at $505-550 \mathrm{~nm}$ by a photomultiplier detector, whereas RFP fluorescence was excited by a $543 \mathrm{~nm}$ HeNe laser and detected at 565-621 nm.

CA $(1 \mu \mathrm{M})$ and LTR $(1 \mu \mathrm{M})$ Red (Invitrogen) were added into BY-2 media for 12 and $3 \mathrm{~h}$, respectively, before confocal imaging. GFP fluorescence was excited by a $488 \mathrm{~nm}$ argon laser and detected at $505-550 \mathrm{~nm}$ by a photomultiplier detector, and LTR fluorescence was excited by a $543 \mathrm{~nm}$ HeNe laser and detected at $565-621 \mathrm{~nm}$. At least 10 sets of images were obtained thrice BY-2 cells for quantification analysis. GFP or LTR punctae were counted per cell according to 10 sets of images field of vision.

\subsection{Pull Down Assays}

pENTR clones in ATG8a were mobilized using the LR Clonase II (Life Technologies) into the Gateway destination vector pDEST17 (Figure S9) for His-ATG8a. His-ATG8a was expressed in E. coli at 
$13^{\circ} \mathrm{C}$ for 2 days after isopropyl $\beta$-D-1-thiogalactopyranoside induction. Purificating ATG8a protein was used with Ni-NTA agarose (QIAGEN). For the pull down assay, Agrobacterium tumefaciens RGS1-GFP, RGS1 ${ }^{1-283}$-GFP, GFP, RGS1 ${ }^{1-413}$-GFP, RGS1 $1^{1-283,414-459}$-GFP, RGS1 ${ }^{1-250}$-GFP, and RGS1 ${ }^{14-250}$-GFP [53] were transiently expressed in N. benthamiana for 3 days. Transient expression in tobacco was determined as previously described [54], except for the infiltration buffer $\left(10 \mathrm{mM} \mathrm{MgCl}_{2}, 10 \mathrm{mM} \mathrm{MES}\right.$, and $150 \mu \mathrm{M}$ acetosyringone). The harvested sample was ground in liquid nitrogen and suspended in a buffer (100 mM Tris-HCl pH7.5), $150 \mathrm{mM} \mathrm{NaCl}, 1 \mathrm{mM}$ ethylenediaminetetraacetic acid (EDTA), 0.5\% Nonidet P-40, plus protease inhibitor cocktail (100X, $100 \mathrm{mM}$ phenylmethylsulfonyl fluoride (PMSF), $1 \mu \mathrm{g} / \mathrm{mL}$ aprotinin, $1 \mu \mathrm{g} / \mathrm{mL}$ leupeptin, and $1 \mu \mathrm{g} / \mathrm{mL}$ pepstatin) and phosphatase inhibitor cocktail (100X, $1 \mathrm{mM}$ $\mathrm{Na}_{3} \mathrm{VO}_{4}, 1 \mathrm{mM} \mathrm{NaF}$ ). After centrifugation at $12,000 \times g$ for $12 \mathrm{~min}$, the supernatants were set for pull down assay.

ATG8a protein was incubated with the above protein extracts of RGS1 (and its truncations)-GFP or GFP and was expressed for $2 \mathrm{~h}$ at $4{ }^{\circ} \mathrm{C}$. The beads were washed thrice with the extraction buffer, and proteins were analyzed by sodium dodecyl sulfate polyacrylamide gel electrophoresis (SDS-PAGE). The RGS1 (and its truncations)-GFP and GFP were detected by Western blotting using the GFP antibody (JL-8 Monoclonal Antibody, Fisher, Invitrogen, Waltham, MA, USA).

\subsection{Immunoblot Analyses}

The total amount of AtRGS1-TAP (AtRGS1 encoding amino acids 1-459) was subcloned to pEarleyGate205 (C-terminal TAP) for quantitative analysis by immunoblots. AtRGS1 tagged with TAP [48] was detected with peroxidase anti-peroxidase soluble complex (PAP). RGS1-TAP seedlings were used in all cases to quantitate AtRGS1. Plants expressing the autophagy marker GFP-ATG8a were used to quantitate autophagic flux using an antibody directed against GFP (Roche). Plant-actin (E12-053) was obtained from Enogene®Biotech (New York, NY, United States).

RGS1-TAP and GFP-ATG8a seedling extracts were suspended in buffer A (50 mM Tris- $\mathrm{HCl} \mathrm{pH}$ 7.5), $150 \mathrm{mM} \mathrm{NaCl}, 5 \mathrm{mM}$ EDTA, 0.2\% Triton X-100, 0.2\% Nonidet P-40, and 1:100 PMSF (stock $60 \mathrm{mM}$ and $2 \%$ ABS-14, $1 \% \beta$-mercaptoethanol) were centrifuged twice at $12,000 \mathrm{rpm}$ for $15 \mathrm{~min}$. Protein concentration was measured with BIO-RAD Protein Assay. $\beta$-actin levels were analyzed as loading controls for different conditions [28].

\subsection{Confocal Microscopy}

The images were obtained in Zeiss LSM 710 confocal laser-scanning microscope (Carl Zeiss Microscopy $\mathrm{GmbH}$, Jena, Germany) and analyzed with Aim Image Browser Image Processing software.

For the observation of seedlings' roots autophagosomes. Autophagosomes labeled by GFP-ATG8a in root cells of GFP-ATG8a plants with incubation in $1 \mu \mathrm{M}$ concanamycin A (CA) for $12 \mathrm{~h}$. For each D-glucose condition, at least two (typically three or four) seedlings were imaged. GFP fluorescence was excited by a $488 \mathrm{~nm}$ argon laser and detected at $505-550 \mathrm{~nm}$ by a photomultiplier detector $[3,28]$. At least 10 sets of images from seven seedlings were obtained for quantification analysis (autophagosomes were counted by the number of GFP points at every root cell in 10 images).

For observation of co-localization of AtRGS1 and autophagosomes with RFP-RGS/GFP-ATG8a seedlings, for each D-glucose condition, at least two (typically three or four) seedlings were imaged. Red fluorescence was excited by a $488 \mathrm{~nm}$ argon laser and detected at $505-550 \mathrm{~nm}$ by a photomultiplier detector, and GFP fluorescence was excited by a $543 \mathrm{~nm}$ HeNe laser and detected at 565-621 nm.

For observations of co-localization of NtRGS1 (its truncations) and autophagosomes with BY-2, please see the above "Co-localization of RGS1 and autophagosome".

RGS1-YFP seedlings (7 day old) were treated with 3\% D-glucose (w/v) and FM4-64 for $2 \mathrm{~h}$. Root cells located $2-4 \mathrm{~mm}$ below the cotyledon were imaged with a Zeiss LSM880 using a META system (LCSM; Carl-Zeiss, Jena, Germany) Confocal microscopy with excitation relationship between autophagy and RGS1 at $561 \mathrm{~nm}$ (a multi-Ar ion laser) emission at 603-680 nm was used to detect the autophagsomes. YFP signals were excited by a 514-nm argon laser and its emission was detected at 
$518-588 \mathrm{~nm}$ by a photomultiplier detector. ImageJ plugin was used for image quantification. Digital Images were captured with a $40 \times$ oil immersion objective and analyzed with ZEN software (Carl Zeiss).

\subsection{Statistical Analysis}

All tests were repeated at least three times and the results were analyzed by GraphPad Prism 5 . Statistical analyses were performed using Student's t test $(p<0.05, p<0.01$, and $p<0.001)$. Quantification of the bands on western blots was performed using image analyzing software, Image J $[48,49]$. Each value was the mean \pm S.D. of three independent replicates.

Supplementary Materials: Supplementary materials can be found at http://www.mdpi.com/1422-0067/20/17/ 4190/s1.

Author Contributions: Y.J., M.S. and J.W. designed the research. Y.J. performed the research. Y.J., M.S. and J. W. analyzed the data and prepared figures. Y.J. wrote the manuscript in consultation with M.S. and J.W., W.C. contributed reagents/materials/analysis tools.

Acknowledgments: This research was supported by the National Natural Science Foundation of China (Grants 31570256 and 31170250), and the Natural Science Foundation of Guangdong Province, China (Grant 2014A030313420), study abroad scholarship of South China Normal University, and a grant from the science and technology project of Guangzhou (Grant No.201805010002). We are grateful to Alan M. Jones (University of North Carolina, Chapel Hill, USA), RGS1-TAP experiments in this paper were finished in Jones lab (NIGMS (R01GM065989) and NSF (MCB-0718202 to A.M.J.). The work of M.S. (BY2 transformation) was supported by the Ministry of Education, Youth and Sports of the Czech Republic (NPUI LO1417; LD15149 - supervised by Lukas Fischer). We are grateful to Lirong Huang (ShangHai Normal University) for providing agrobacterium. RGS1 ${ }^{1-283}$-GFP, RGS1 ${ }^{1-413}$-GFP, RGS1 1-283,414-459-GFP, RGS1 ${ }^{1-250}$-GFP, RGS1 ${ }^{14-250}$-GFP. We also thank Li Faqiang (Department of Genetics, University of Wisconsin, Madison, WI, USA) for providing the transgenic Arabidopsis expressing GFP-ATG8a.We would like to thank Professor Hengming Ke, UNC-Chapel Hill School of Medicine of USA and Zheng Qing Fu, University of South Carolina for proofreading of the manuscript.

Conflicts of Interest: The authors declare no conflict of interest.

\section{References}

1. Limanaqi, F.; Biagioni, F.; Busceti, C.L.; Ryskalin, L.; Soldani, P.; Frati, A.; Fornai, F. Cell Clearing Systems Bridging Neuro-Immunity and Synaptic Plasticity. Int. J. Mol. Sci. 2019, 20, 2197. [CrossRef] [PubMed]

2. Farré, J.-C.; Subramani, S. Peroxisome turnover by micropexophagy: An autophagy-related process. Trends Cell Biol. 2004, 14, 515-523. [CrossRef] [PubMed]

3. Yan, Q.; Wang, J.; Fu, Z.Q.; Chen, W. Endocytosis of AtRGS1 Is Regulated by the Autophagy Pathway after D-Glucose Stimulation. Front. Plant Sci. 2017, 8, 1229. [CrossRef] [PubMed]

4. Kroemer, G.; Jäättelä, M. Lysosomes and autophagy in cell death control. Nat. Rev. Cancer 2005, 5, 886. [CrossRef] [PubMed]

5. Bizargity, P.; Schröppel, B. Autophagy: Basic Principles and Relevance to Transplant Immunity: Autophagy and Transplant Immunity. Am. J. Transplant. 2014, 14, 1731-1739. [CrossRef] [PubMed]

6. Mizushima, N.; Levine, B.; Cuervo, A.M.; Klionsky, D.J. Autophagy fights disease through cellular self-digestion. Nature 2008, 451, 1069. [CrossRef] [PubMed]

7. Mehrpour, M.; Esclatine, A.; Beau, I.; Codogno, P. Overview of macroautophagy regulation in mammalian cells. Cell Res. 2010, 20, 748. [CrossRef] [PubMed]

8. Bassham, D.C. Plant autophagy-more than a starvation response. Curr. Opin. Plant Biol. 2007, 10, 587-593. [CrossRef] [PubMed]

9. Yang, Z.; Klionsky, D.J. An overview of the molecular mechanism of autophagy. In Autophagy in infection and immunity; Springer: Berlin/Heidelberg, Germany, 2009; pp. 1-32.

10. Mijaljica, D.; Prescott, M.; Devenish, R.J. Microautophagy in mammalian cells: Revisiting a 40-year-old conundrum. Autophagy 2011, 7, 673-682. [CrossRef] [PubMed]

11. Orenstein, S.J.; Cuervo, A.M. Chaperone-mediated autophagy: Molecular mechanisms and physiological relevance. In Proceedings of the Seminars in cell \& developmental biology; Elsevier: Amsterdam, The Netherlands, 2010; pp. 719-726. 
12. Reumann, S.; Voitsekhovskaja, O.; Lillo, C. From signal transduction to autophagy of plant cell organelles: Lessons from yeast and mammals and plant-specific features. Protoplasma 2010, 247, 233-256. [CrossRef] [PubMed]

13. Bárány, I.; Berenguer, E.; Solís, M.-T.; Pérez-Pérez, Y.; Santamaría, M.E.; Crespo, J.L.; Risueño, M.C.; Díaz, I.; Testillano, P.S. Autophagy is activated and involved in cell death with participation of cathepsins during stress-induced microspore embryogenesis in barley. J. Exp. Bot. 2018, 69, 1387-1402. [CrossRef] [PubMed]

14. Rolland, F.; Moore, B.; Sheen, J. Sugar sensing and signaling in plants. The plant cell 2002, 14, S185-S205. [CrossRef] [PubMed]

15. Rolland, F.; Winderickx, J.; Thevelein, J.M. Glucose-sensing mechanisms in eukaryotic cells. Trends Biochem. Sci. 2001, 26, 310-317. [CrossRef]

16. Huang, J.-P.; Tunc-Ozdemir, M.; Chang, Y.; Jones, A.M. Cooperative control between AtRGS1 and AtHXK1 in a WD40-repeat protein pathway in Arabidopsis thaliana. Front. Plant Sci. 2015, 6, 851. [CrossRef] [PubMed]

17. Johnston, C.A.; Taylor, J.P.; Gao, Y.; Kimple, A.J.; Grigston, J.C.; Chen, J.-G.; Siderovski, D.P.; Jones, A.M.; Willard, F.S. GTPase acceleration as the rate-limiting step in Arabidopsis G protein-coupled sugar signaling. Proc. Natl. Acad. Sci. USA 2007, 104, 17317-17322. [CrossRef] [PubMed]

18. Jones, J.C.; Duffy, J.W.; Machius, M.; Temple, B.R.; Dohlman, H.G.; Jones, A.M. The crystal structure of a self-activating $G$ protein $\alpha$ subunit reveals its distinct mechanism of signal initiation. Sci. Signal 2011, 4, ra8. [CrossRef] [PubMed]

19. Chen, J.-G.; Willard, F.S.; Huang, J.; Liang, J.; Chasse, S.A.; Jones, A.M.; Siderovski, D.P. A seventransmembrane RGS protein that modulates plant cell proliferation. Science 2003, 301, 1728-1731. [CrossRef] [PubMed]

20. Chen, J.-G.; Jones, A.M. AtRGS1 function in Arabidopsis thaliana. In Methods in enzymology; Elsevier: Amsterdam, The Netherlands, 2004; pp. 338-350.

21. Urano, D.; Chen, J.-G.; Botella, J.R.; Jones, A.M. Heterotrimeric G protein signalling in the plant kingdom. Open Biol. 2013, 3, 120186. [CrossRef]

22. Zhong, C.-L.; Zhang, C.; Liu, J.-Z. Heterotrimeric G protein signaling in plant immunity. J. Exp. Bot. 2018, 70, 1109-1118. [CrossRef]

23. Thompson, A.R.; Doelling, J.H.; Suttangkakul, A.; Vierstra, R.D. Autophagic nutrient recycling in Arabidopsis directed by the ATG8 and ATG12 conjugation pathways. Plant Physiol. 2005, 138, 2097-2110. [CrossRef]

24. Klionsky, D.J.; Baehrecke, E.H.; Brumell, J.H.; Chu, C.T.; Codogno, P.; Cuervo, A.M.; Debnath, J.; Deretic, V.; Elazar, Z.; Eskelinen, E.-L.; et al. A comprehensive glossary of autophagy-related molecules and processes. Autophagy 2011, 7, 1273-1294. [CrossRef]

25. Kim, J.; Lee, H.; Lee, H.N.; Kim, S.-H.; Shin, K.D.; Chung, T. Autophagy-related proteins are required for degradation of peroxisomes in Arabidopsis hypocotyls during seedling growth. Plant Cell 2013, 25, 4956-4966. [CrossRef]

26. Shin, K.D.; Lee, H.N.; Chung, T. A revised assay for monitoring autophagic flux in Arabidopsis thaliana reveals involvement of AUTOPHAGY-RELATED9 in autophagy. Mol. Cells 2014, 37, 399. [CrossRef]

27. Meijer, A.J. Autophagy research: Lessons from metabolism. Taylor E Francis 2009, 5, 3-5.

28. Wang, X.; Gao, Y.; Yan, Q.; Chen, W. Salicylic acid promotes autophagy via NPR3 and NPR4 in Arabidopsis senescence and innate immune response. Acta Physiol. Plant 2016, 38, 241. [CrossRef]

29. Gao, Y.; Wang, X.; Ma, C.; Chen, W. EDS1-mediated activation of autophagy regulates Pst DC3000 (AvrRps4)-induced programmed cell death in Arabidopsis. Acta Physiol. Plant. 2016, 38, 150. [CrossRef]

30. Klionsky, D.J. For the last time, it is GFP-Atg8, not Atg8-GFP (and the same goes for LC3). Taylor E Francis 2011, 7, 1093-1094.

31. Mizushima, N.; Yoshimori, T.; Levine, B. Methods in mammalian autophagy research. Cell 2010, 140, 313-326. [CrossRef]

32. Agholme, L.; Hallbeck, M.; Benedikz, E.; Marcusson, J.; Kagedal, K. Amyloid- $\beta$ secretion, generation, and lysosomal sequestration in response to proteasome inhibition: Involvement of autophagy. J. Alzheimer's Dis. 2012, 31, 343-358. [CrossRef]

33. Watanabe-Asano, T.; Kuma, A.; Mizushima, N. Cycloheximide inhibits starvation-induced autophagy through mTORC1 activation. Biochem. and Biophys. Res. Commun. 2014, 445, 334-339.

34. Nocarova, E.; Fischer, L. Cloning of transgenic tobacco BY-2 cells; an efficient method to analyse and reduce high natural heterogeneity of transgene expression. BMC Plant Biol. 2009, 9, 44. [CrossRef] 
35. Hanamata, S.; Kurusu, T.; Okada, M.; Suda, A.; Kawamura, K.; Tsukada, E.; Kuchitsu, K. In vivo imaging and quantitative monitoring of autophagic flux in tobacco BY-2 cells. Plant Signaling Behav. 2013, 8, e22510. [CrossRef]

36. Munafó, D.B.; Colombo, M.I. A novel assay to study autophagy: Regulation of autophagosome vacuole size by amino acid deprivation. J. Cell Sci. 2001, 114, 3619-3629.

37. Liu, Y.; Schiff, M.; Czymmek, K.; Tallóczy, Z.; Levine, B.; Dinesh-Kumar, S. Autophagy regulates programmed cell death during the plant innate immune response. Cell 2005, 121, 567-577. [CrossRef]

38. Dong, J.; Chen, W. The role of autophagy in chloroplast degradation and chlorophagy in immune defenses during Pst DC3000 (AvrRps4) infection. PLoS ONE 2013, 8, e73091. [CrossRef]

39. Yano, K.; Matsui, S.; Tsuchiya, T.; Maeshima, M.; Kutsuna, N.; Hasezawa, S.; Moriyasu, Y. Contribution of the plasma membrane and central vacuole in the formation of autolysosomes in cultured tobacco cells. Plant Cell Physiol. 2004, 45, 951-957. [CrossRef]

40. Journo, D.; Winter, G.; Abeliovich, H. Monitoring Autophagy in Yeast using FM 4-64 Fluorescence. Methods Enzymol. 2008, 451, 79-88.

41. Oh-ye, Y.; Inoue, Y.; Moriyasu, Y. Detecting autophagy in Arabidopsis roots by membrane-permeable cysteine protease inhibitor E-64d and endocytosis tracer FM4-64. Plant Signaling Behav. 2011, 6, 1946-1949. [CrossRef]

42. Wang, Y.; Nishimura, M.T.; Zhao, T.; Tang, D. ATG2, an autophagy-related protein, negatively affects powdery mildew resistance and mildew-induced cell death in Arabidopsis. Plant J. 2011, 68, 74-87. [CrossRef]

43. De Vries, L.; Fischer, T.; Tronchere, H.; Brothers, G.M.; Strockbine, B.; Siderovski, D.P.; Farquhar, M.G. Activator of $\mathrm{G}$ protein signaling 3 is a guanine dissociation inhibitor for G $\alpha$ i subunits. Proc. Natl. Acad. Sci. USA 2000, 97, 14364-14369. [CrossRef]

44. Zheng, Y.; Brockie, P.J.; Mellem, J.E.; Madsen, D.M.; Maricq, A.V. Neuronal control of locomotion in C. elegans is modified by a dominant mutation in the GLR-1 ionotropic glutamate receptor. Neuron 1999, 24, 347-361. [CrossRef]

45. Lee, J.-K.; Kannarkat, G.T.; Chung, J.; Lee, H.J.; Graham, K.L.; Tansey, M.G. RGS10 deficiency ameliorates the severity of disease in experimental autoimmune encephalomyelitis. J. Neuroinflamm. 2016, 13, 24. [CrossRef]

46. Xiong, Y.; Sheen, J. Rapamycin and glucose-target of rapamycin (TOR) protein signaling in plants. J. Biol. Chem. 2012, 287, 2836-2842. [CrossRef]

47. Clough, S.J.; Bent, A.F. Floral dip: A simplified method for Agrobacterium-mediated transformation of Arabidopsis thaliana. Plant J. 1998, 16, 735-743. [CrossRef]

48. Urano, D.; Phan, N.; Jones, J.C.; Yang, J.; Huang, J.; Grigston, J.; Taylor, J.P.; Jones, A.M. Endocytosis of the seven-transmembrane RGS1 protein activates G-protein-coupled signalling in Arabidopsis. Nat. Cell Biol. 2012, 14, 1079. [CrossRef]

49. Fu, Y.; Lim, S.; Urano, D.; Tunc-Ozdemir, M.; Phan, N.G.; Elston, T.C.; Jones, A.M. Reciprocal encoding of signal intensity and duration in a glucose-sensing circuit. Cell 2014, 156, 1084-1095. [CrossRef]

50. Klopffleisch, K.; Phan, N.; Augustin, K.; Bayne, R.S.; Booker, K.S.; Botella, J.R.; Carpita, N.C.; Carr, T.; Chen, J.-G.; Cooke, T.R.; et al. Arabidopsis G-protein interactome reveals connections to cell wall carbohydrates and morphogenesis. Mol. Syst. Biol. 2011, 7, 532. [CrossRef]

51. Grigston, J.C.; Osuna, D.; Scheible, W.-R.; Liu, C.; Stitt, M.; Jones, A.M. D-glucose sensing by a plasma membrane regulator of $G$ signaling protein, AtRGS1. FEBS Lett. 2008, 582, 3577-3584. [CrossRef]

52. Nagata, T.; Nemoto, Y.; Hasezawa, S. Tobacco BY-2 cell line as the "HeLa" cell in the cell biology of higher plants. In International Review of Cytology; Elsevier: Amsterdam, The Netherlands, 1992; Volume 132, pp. 1-30.

53. Hu, G.; Suo, Y.; Huang, J. A crucial role of the RGS domain in trans-Golgi network export of AtRGS1 in the protein secretory pathway. Mol. Plant 2013, 6, 1933-1944. [CrossRef]

54. Liu, L.; Zhang, Y.; Tang, S.; Zhao, Q.; Zhang, Z.; Zhang, H.; Dong, L.; Guo, H.; Xie, Q. An efficient system to detect protein ubiquitination by agroinfiltration in Nicotiana benthamiana. Plant J. 2010, 61, 893-903. [CrossRef]

(C) 2019 by the authors. Licensee MDPI, Basel, Switzerland. This article is an open access article distributed under the terms and conditions of the Creative Commons Attribution (CC BY) license (http://creativecommons.org/licenses/by/4.0/). 